\title{
BIOGEOGRAPHY OF NORTH AMERICAN BEETLES: NEW PERSPECTIVES FROM THE QUATERNARY FOSSIL RECORD
}

\author{
ELIAS, Scott A., Institute of Arctic and Alpine Research, CB 450, University of \\ Colorado, Boulder, CO 80309-0450, U.S.A.
}

The study of insect biogeography often employs only modern or historical data on the distributions of species in attempts to determine their geographic origins and to reconstruct their distributional shifts through time. The Quaternary fossil record is now providing factual information on the former ranges of modern species that may invalidate biogeographic theories based solely on modern data. For instance, it has been suggested that Pleistocene glaciations may have caused the extinction of many sedentary insects in North America, and that Pleistocene environmental stresses on North American insects probably selected for relatively vagile taxa. The fossil evidence refutes these statements; even flightless, heavy-bodied weevil species shifted their distributions quite dramatically during the late Pleistocene, in response to large-scale climatic change. Furthermore, paleontologists have discovered only one possible extinction of a beetle species in the Quaternary fossil record of North America, out of the more than 1000 extant species that have been found in Quaternary fossil assemblages. Not only is species vagility greater than expected, even for sedentary species, the ability of beetles to shift distributions in response to environmental change has contributed to species longevity; few if any taxa have evolved during the last million or more years. This is because nearly constant distributional shifts (on a geologic/evolutionary time scale) have kept their gene pools well-mixed. Populations have not been isolated sufficiently long to become genetically distinct.

As climates changed from glacial to interglacial periods, beetle faunas in the midlatitudes underwent wholesale changes in composition. Cold-adapted species replaced thermophilous species at the onset of glaciations, and the process was reversed at the termination of each glaciation. Warm-adapted beetles now living in the Mediterranean region invaded Britain during the last interglaciation (ca. 130,000 years before present), only to be replaced by arctic taxa now found in northern Scandinavia and Siberia during the last glaciation. In North America, temperate faunas in mid-western states were replaced by arctic and alpine species at the onset of the Wisconsin glaciation. As regional climates warmed, about 13,000 yr BP, these cold-adapted beetles were extirpated from the regions south of the waning ice sheets; some species were able to become re-established in the alpine tundra zone on the tops of high peaks in the Rocky Mountains.

In the Chihuahuan Desert, the Wisconsin glacial beetle fauna reflected cooler, more mesic climates than are found there today. The Wisconsin faunal assemblages contained mixtures of species not found together in any one modern region. At the end of the glacial period, many species shifted their distributions to regions outside of that desert. 